\title{
Posttraumatic and iatrogenic foreign bodies in the heart: Report of fourteen cases and review of the literature
}

Guglielmo Maria Actis Dato, $\mathrm{MD}^{\mathrm{a}}$

Anna Arslanian, $\mathrm{MD}^{\mathrm{b}}$

Paolo Di Marzio, MD ${ }^{\mathrm{b}}$

Pier Luigi Filosso, $\mathrm{MD}^{\mathrm{b}}$

Enrico Ruffini, MD ${ }^{\mathrm{b}}$
From the Divisions of Cardiac Surgery ${ }^{\mathrm{a}}$ and Thoracic Surgery, ${ }^{\mathrm{b}}$ University of Torino, Torino, Italy.

Received for publication March 18, 2002; revisions requested April 3, 2002; revisions received April 17, 2002; accepted for publication April 23, 2002.

Address for reprints: Enrico Ruffini, MD, Thoracic Surgery, University of Torino, 3, Via Genova 10126, Torino, Italy (E-mail: enrico.ruffini@unito.it).

J Thorac Cardiovasc Surg 2003;126:408-14

Copyright $\odot 2003$ by The American Association for Thoracic Surgery

$0022-5223 / 2003 \$ 30.00+0$

doi:10.1016/S0022-5223(03)00399-4
Objective: Our experience with posttraumatic and iatrogenic foreign bodies in the heart is presented and discussed along with a review of the literature on this subject.

Summary background data: Posttraumatic or iatrogenic foreign bodies in the heart can be treated either conservatively or surgically. Controversy exists about optimal management.

Methods: Fourteen cases of posttraumatic or iatrogenic foreign bodies in the heart observed between 1955 and 2000 were studied. Our series includes the following: bullets into the right or left ventricle (4 cases); needles in the left ventricle, atrium, and pulmonary artery (3 cases); retained catheter fragments in the right ventricle, right atrium, or in the pulmonary artery (4 cases); a grenade fragment into the right atrium ( 1 case); a circular saw fragment into the right ventricle (1 case); and a commissurotomy ring into the left atrium (1 case).

Results: Foreign bodies were removed when in the cardiac cavities (1 case); when in the presence of associated risk factors like embolism, arrhythmia, or infection (3 cases); and when in the presence of associated signs or symptoms including cardiac tamponade ( 2 cases), arrhythmia ( 1 case), fever ( 2 cases), or anxiety (1 case). Removal was accomplished by a thoracotomy ( 7 cases) or sternotomy ( 2 cases), with (3 cases) or without cardiopulmonary bypass, or percutaneously (1 case). Four asymptomatic patients were conservatively treated and have no evidence of complications at a median follow-up of 20 years.

Conclusions: The management of foreign bodies in the heart should be individualized: (1) symptomatic foreign bodies should be removed irrespective of their location; (2) asymptomatic foreign bodies diagnosed immediately after the injury with associated risk factors should be removed; (3) asymptomatic foreign bodies without associated risks factors or diagnosed late after the injury may be treated conservatively, particularly if they are completely embedded in the myocardium or in the pericardium.

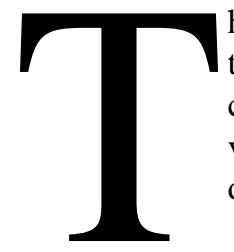

he presence of a foreign body in the heart or great vessels can be due to a war trauma as in the case of blunt shot or an air rifle. ${ }^{1,2}$ Another cause can be the migration of a catheter fragment from a peripheral vessel to the heart or a needle migration to the heart as in the case of drug addicts. ${ }^{3-6}$

A needle lost in the baby's bed subsequently penetrating in the baby's thorax can be the cause of fever and weight loss in childhood but may also be observed occasionally years later. ${ }^{7}$ A possible embolization of a Kirschner wire to the heart or great vessels is also reported after orthopedic surgery. ${ }^{8}$ A pacemaker wire 
TABLE 1. Foreign bodies in the heart (1955-2000)

\begin{tabular}{|c|c|c|c|c|c|c|c|c|c|}
\hline $\begin{array}{l}\text { Age } \\
\text { (y) }\end{array}$ & Sex & $\begin{array}{c}\text { Time between } \\
\text { penetration } \\
\text { and diagnosis }\end{array}$ & Urgency & Symptoms & Localization & Type & Site & Surgery & $\begin{array}{c}\text { Follow-up } \\
\text { (years) }\end{array}$ \\
\hline 47 & M & $2 \mathrm{~h}$ & Emergency & No & Right ventricle & Bullet & Intramural & $\mathrm{N}$ & 25 \\
\hline 32 & M & $3 \mathrm{~h}$ & Emergency & Cardiac tamponade & Right ventricle & Bullet & Transmural & $Y$ & 29 \\
\hline 9 & M & $3 y$ & Elective & No & Right ventricle & Bullet 4 mm & Intracavitary & $\mathrm{N}$ & 32 \\
\hline 31 & M & $2 \mathrm{~h}$ & Emergency & No & Left ventricle & Bullet $6.35 \mathrm{~mm}$ & Intramural & $\mathrm{N}$ & 39 \\
\hline 2.5 & M & $2 y$ & Elective & Fever & Left ventricle & Needle & $\begin{array}{c}\text { Transmural and } \\
\text { intracavitary }\end{array}$ & $Y$ & 40 \\
\hline 9 & M & 8 years & Elective & Fever & Left atrium & Needle & $\begin{array}{c}\text { Transmural and } \\
\text { intracavitary }\end{array}$ & Y & 33 \\
\hline 51 & M & $45 y$ & Elective & No & $\begin{array}{c}\text { Pulmonary } \\
\text { artery }\end{array}$ & Needle & Intravascular & $\mathrm{N}$ & 19 \\
\hline 12 & M & $1 \mathrm{~h}$ & Urgent & No & Right ventricle & $\begin{array}{l}\text { Venous } \\
\text { catheter }\end{array}$ & $\begin{array}{l}\text { Intravascular } \\
\text { iatrogenic }\end{array}$ & Y & 21 \\
\hline 62 & M & $1 \mathrm{~h}$ & Urgent & No & Right atrium & $\begin{array}{c}\text { Swan-Ganz } \\
\text { catheter }\end{array}$ & $\begin{array}{l}\text { Intravascular } \\
\text { iatrogenic }\end{array}$ & $\mathrm{Y}^{*}$ & 6 \\
\hline 22 & M & $10 \mathrm{~d}$ & Urgent & Anxiety & $\begin{array}{c}\text { Pulmonary } \\
\text { artery }\end{array}$ & $\begin{array}{l}\text { Venous } \\
\text { catheter }\end{array}$ & $\begin{array}{l}\text { Intravascular } \\
\text { iatrogenic }\end{array}$ & Y & 18 \\
\hline 32 & M & $1 \mathrm{~m}$ & Urgent & Thoracic pain & $\begin{array}{l}\text { Pulmonary } \\
\text { artery }\end{array}$ & $\begin{array}{l}\text { Venous } \\
\text { catheter }\end{array}$ & $\begin{array}{l}\text { Intravascular } \\
\text { iatrogenic }\end{array}$ & $\mathrm{Y} \dagger$ & 1 \\
\hline 51 & M & $20 y$ & Elective & Arrhythmia & Right atrium & $\begin{array}{l}\text { Grenade } \\
\text { fragment }\end{array}$ & Intramural & Y & 17 \\
\hline 45 & M & 12 hours & Emergency & Tamponade & Right ventricle & $\begin{array}{c}\text { Circular saw } \\
\text { fragment }\end{array}$ & Transmural & $Y^{*}$ & 11 \\
\hline 30 & $\mathrm{~F}$ & $12 y$ & Elective & No & Left atrium & $\begin{array}{l}\text { Valvulotomy } \\
\text { ring }\end{array}$ & $\begin{array}{l}\text { Intravascular } \\
\text { iatrogenic }\end{array}$ & $Y^{*}$ & 7 \\
\hline
\end{tabular}

*Fragment removed during cardiopulmonary bypass.

tPercutaneous removal.

fragment represents a possible complication after cardiac surgery in patients with definitive pacing. ${ }^{9}$ Currently, diagnosis may be easily made by echocardiography, although it was more difficult when only conventional radiology was available as in earlier reports. ${ }^{10-15}$

The foreign body can be removed with a surgical or percutaneous approach according to the dimensions and composition of the foreign body. ${ }^{16,17}$ Controversy exists about optimal treatment in asymptomatic patients in whom the risk of embolization is low and a surgical procedure can be more dangerous than conservative treatment. ${ }^{10,18-20}$

To more clearly define optimal management of retained foreign bodies in the heart, we review our experience in 14 cases observed from 1955 to 2000 and review the literature on the subject.

\section{Patients and Methods}

Between 1955 and 2000 we observed 14 patients with a foreign body in the heart or the great vessels. There were 13 male patients and 1 female patient, with a mean age of 31 years (range 2.5-62 years). Symptoms were present in 7 patients (Table 1). Surgery was performed in 9 cases; in 1 case, percutaneous removal was possible. Postoperative course was uneventful in all patients. The remaining 4 patients received conservative treatment.
A clinical follow-up from 1 to 39 years (median 20 years) was possible by our outpatient office or by direct telephone contact.

\section{Bullets in the Heart Cavities (4 Cases)}

PATIENT 1. A 47-year-old man arrived at our hospital after a shooting. Angiographic study showed a bullet in the right ventricle. The clinical conditions were stable and conservative treatment was used. After 25 years, the patient is alive and well.

PATIENT 2. A 32-year-old man arrived at our hospital after a shooting. A chest x-ray film showed 2 bullets in the right ventricle and signs of pericardial effusion with an initial cardiac tamponade. A left anterior thoracotomy was performed; the bullets were removed and $200 \mathrm{~mL}$ of blood was drained from the pericardial space. After 29 years the patient is alive and well.

PATIENT 3. A 9-year-old boy underwent chest radiography during an epidemiologic study. A 4-mm bullet was evidenced in the outflow tract of the right ventricle (Figure 1). A gunshot in a limb had occurred 3 years before. Conservative treatment was chosen. The patient remains asymptomatic after 32 years.

PATIENT 4. A 31-year-old-man had attempted suicide. A chest $\mathrm{x}$-ray film showed a $6.35-\mathrm{mm}$ bullet in the anterolateral wall of the left ventricle. The patient was asymptomatic and conservative treatment was chosen. After 39 years the patient is alive and well. 


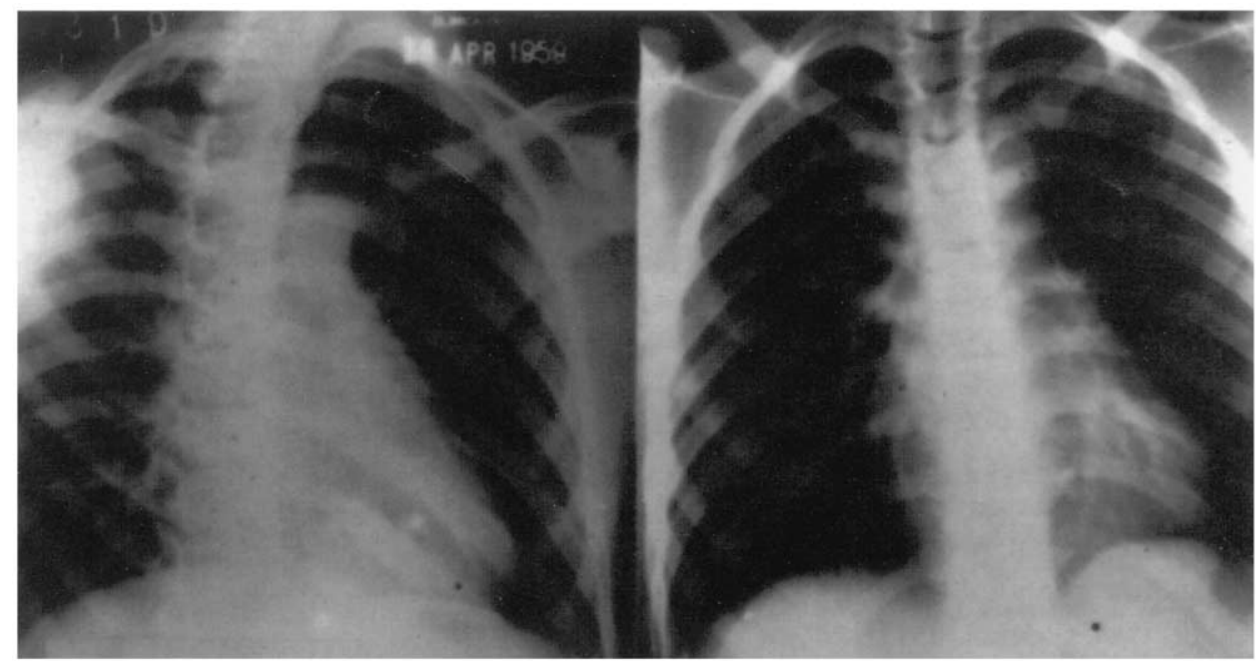

Figure 1. Chest $x$-ray films showing a bullet localized in the right ventricle after being propelled through the inferior vena cava to the right atrium from the penetration site in the leg.

\section{Needles in the Heart and Pulmonary Artery (3 Cases)}

PATIENT 1. A 2.5-year-old boy with recurrent fever had a needle in the left ventricle as evidenced by a chest x-ray film. The needle had penetrated during movements in the cradle. A left anterior thoracotomy at the fourth intercostal space allowed needle extraction without any other hemostatic maneuver. The needle was partially covered by fibrin and partially embedded in the ventricle, not protruding into the cardiac cavity. Forty years later the patient is alive and well (Figure 2).

PATIENT 2. A 9-year-old boy had recurrent fever. A chest x-ray film showed a needle in the left atrium. Possibly the needle penetrated into the cradle some years before but only few years later the patient became symptomatic. A left thoracotomy was performed at the fourth intercostal space and the needle was easily located because of a partially exposed portion and removed.

PATIENT 3. A 51-year-old man had a fragmented needle on chest radiography, localized in the main pulmonary artery. The foreign body had been present in the heart since he was 6 years old. It probably penetrated with the same mechanism as in the other cases of intracardiac needles but without penetration in the vascular bed. Conservative treatment was adopted. The patient died 19 years later of cancer.

\section{Retained Catheter Fragments in the Heart or Pulmonary Artery (4 Cases)}

PATIENT 1. A 12-year-old boy had an atrial septal defect that was closed during mild hypothermic circulatory arrest with a probe thermal exchange. He received cardiac catheterization through an upper arm vein to evaluate a possible residual shunt. At the end of the procedure, a $10-\mathrm{cm}$ catheter fragment broke and migrated into the right ventricle. A rethoracotomy was necessary. The foreign body was removed with a small incision of the pulmonary artery without cardiopulmonary bypass using mild hypothermic circulatory arrest ( 3 minutes). After 21 years the patient is alive and well.

PATIENT 2. A 62-year-old man had low cardiac output syndrome after coronary artery bypass grafting. A Swan-Ganz catheter (Ed- wards Lifesciences, Irvine, Calif) was necessary for 4 days. Difficulty was experienced during removal of the catheter; a chest $\mathrm{x}$-ray film showed that the catheter was knotted and entrapped in the right atrium. A retoracotomy was undertaken under cardiopulmonary bypass for removal of the Swan-Ganz catheter.

PATIENT 3. A 22-year-old man had a 4-cm retained fragment of a central venous catheter in the right pulmonary artery. The patient, when informed of the foreign body, became anxious and asked for its removal. A right anterior thoracotomy was performed at the fourth intercostal space, and the foreign body was easily located by finger palpation and removed with a small incision in the right pulmonary artery without cardiopulmonary bypass.

PATIENT 4. A 32-year-old man with osteomyelitis had a Groshong catheter (C. R. Bard, Inc, Murray Hill, NJ) inserted for long-term antibiotic therapy. During infusion the patient had thoracic pain and a chest $\mathrm{x}$-ray film showed a foreign body in the right pulmonary artery. Percutaneous removal was successfully performed.

\section{Grenade Fragment in the Left Atrium (1 Case)}

PATIENT 1. A 51-year-old man was admitted to our hospital for recurrent paroxysmal tachyarrhythmia. A standard chest x-ray film showed a grenade fragment near the left atrium close to the superior vena cava junction. Twenty years earlier, during World War II, the patient was involved in a grenade explosion. A right anterior thoracotomy was performed at the sixth intercostal space; the foreign body was located by finger and removed without cardiopulmonary bypass (Figures 3 and 4). In the following years no further arrhythmia was observed, and the patient died 17 years later of an unknown cause.

\section{Fragment of Circular Saw in the Right Ventricle (1 Case)}

PATIENT 1. A 45-year-old man had a fragment of circular saw in the right ventricle, which penetrated while the patient was working and resulted in cardiac tamponade. After drainage, a median ster- 


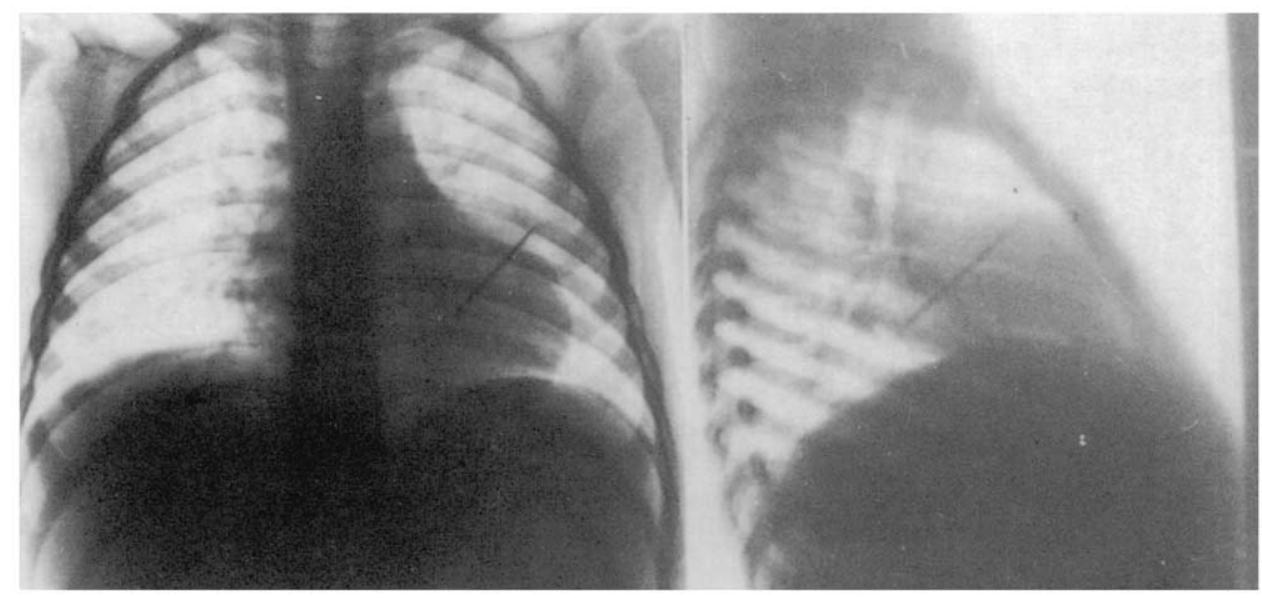

Figure 2. Chest x-ray films of a 2.5-year-old boy with a needle infixed in the left ventricle approaching the cardiac cavity.

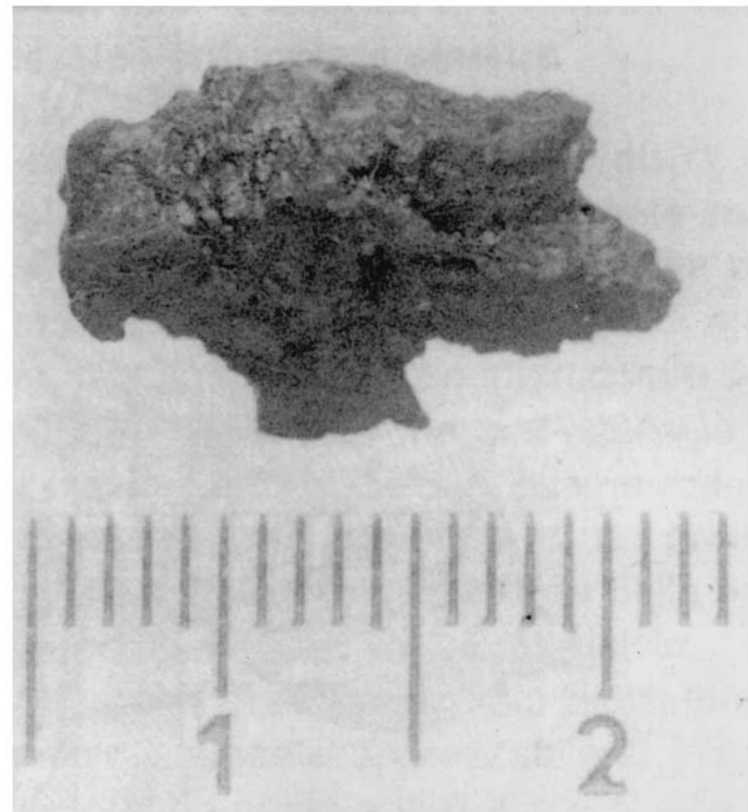

Figure 3. The grenade fragment extracted from the left atrium.

notomy was performed and cardiopulmonary bypass was instituted; the fragment was removed and the right ventricle repaired. The patient is alive and well after 11 years (Figure 5).

\section{Valvulotomy Ring in the Left Atrium (1 Case)}

PATIENT 1. A 30-year-old woman underwent a closed mitral commissurotomy using Dogliotti's ring in 1956; the surgeon left the ring in the left atrium. The patient was treated conservatively for 12 years. A subsequent mitral restenosis required a valve replacement and on this occasion the foreign body was removed. It was fixed to a pulmonary vein. The patient was lost to follow-up after 7 years, at which time she was in good clinical condition (Figure 6).

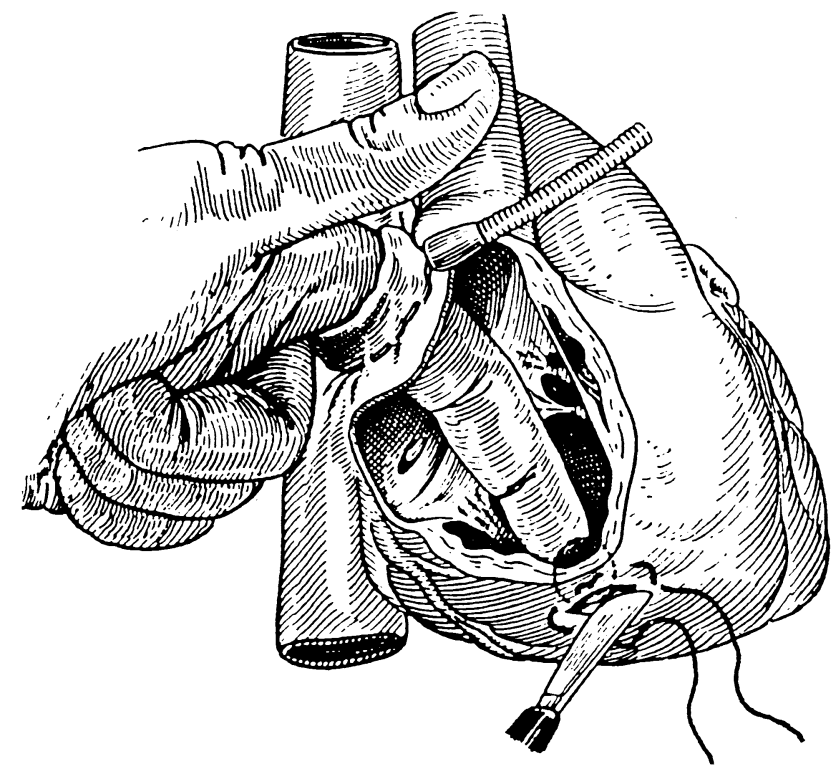

Figure 4. After digital localization of the fragment, the missile was extracted through a small incision in the atrium.

\section{Discussion}

Penetration of a foreign body into the heart may result from either a direct injury to the heart or from embolization to the heart from distal penetration sites. The foreign body in this case may enter the right side of the heart or the pulmonary artery, embolizing through the venous blood flow. ${ }^{10,21,22}$ Embolization depends on the patient's position and on the weight and shape of the missile, being favored by low flow states and hypotension at the time of the injury. Penetrating bullet wounds may cause embolization especially when bullets are of low velocity or of small caliber. ${ }^{23,24}$ From the right side of the heart, the foreign body may be propelled 


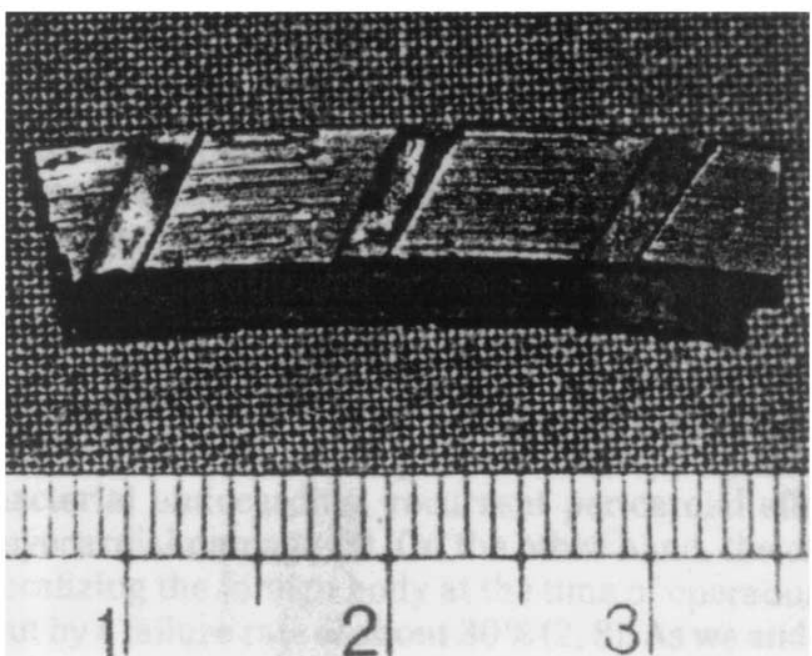

Figure 5. Fragment of the circular saw that penetrated the right ventricle.

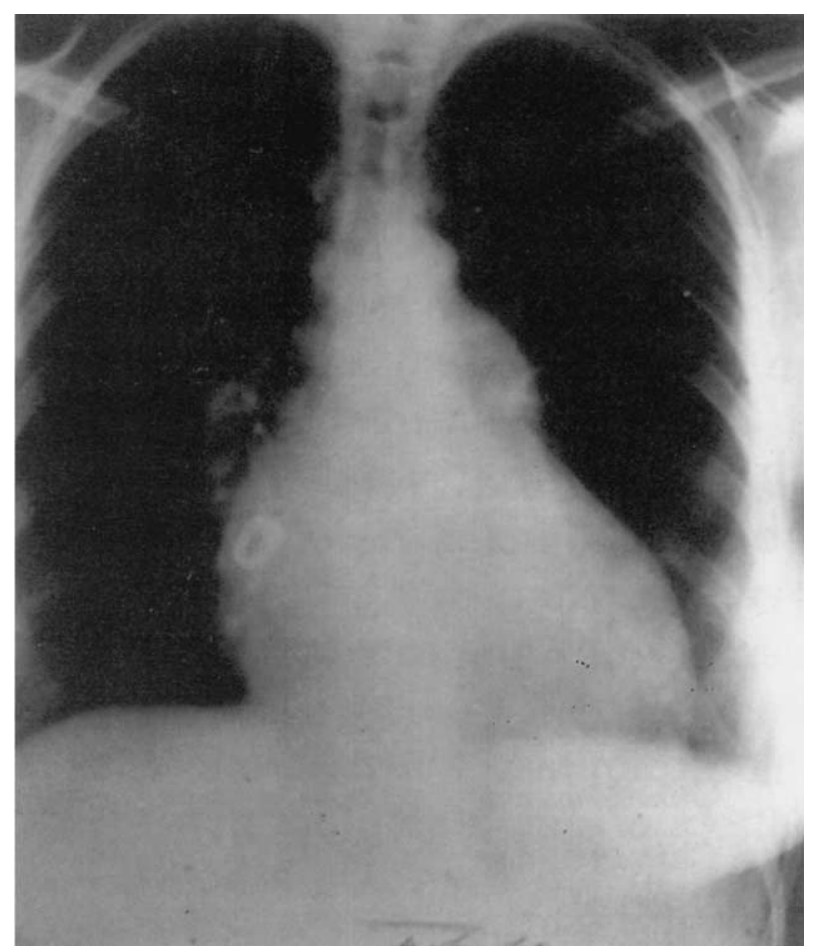

Figure 6. Dogliotti's ring, widely used for closed commissurotomy of the mitral valve during the 1950s and 1960s, which had been left in the left atrium.

into the pulmonary artery, go back to the venous system, or eventually be entrapped in endocardial trabeculations and become encapsulated with fibrous tissue. ${ }^{10}$ Specific localization is necessary in these cases to avoid unnecessary and inappropriate incisions. ${ }^{10}$ Migratory intravascular foreign bodies can produce a confusing picture to the physician evaluating the trauma patient. ${ }^{21}$ Finally, paradoxical embolization occurs when a missile enters the right side of the heart from a peripheral vein and reaches the left side through a patent foramen ovale., ${ }^{4,21}$

Diagnosis of cardiac foreign bodies may be suspected immediately after the injury or incidentally during investigation for another condition when the missile has remained silent for an extended time. The clinical manifestations of a retained foreign body in the heart immediately after the injury are those related to the cardiac injury, including cardiac tamponade and/or bleeding; if the missile did not injure the valves or septa, the patient may also be symptomfree at presentation. When diagnosed later, most cardiac foreign bodies have been entrapped by fibrous tissue and - if the patient is asymptomatic - do not cause particular harm. Finally, in some cases, a patient becomes symptomatic many years after diagnosis of foreign body that had been treated conservatively. ${ }^{10,20}$ Patient histories and chest $\mathrm{x}$-ray films were sufficient in our initial cases to make a correct diagnosis. In other historical reports, diagnosis was suspected with $\mathrm{x}$-ray films and confirmed with fluoroscopy or angiocardiography. ${ }^{1,23}$ In the most recent reports, the missiles were correctly diagnosed and located by echocardiography and computed tomographic scan. ${ }^{5,20,11}$ Intraoperative imaging studies are important to demonstrate migration of the foreign body during patient positioning. ${ }^{20}$ The use of intraoperative transesophageal echocardiography can be useful to identify foreign bodies into the cardiac muscle including bullets or needles. ${ }^{15,20,23}$

Treatment options including surgery or a conservative approach must be tailored case by case in relation to symptoms and possible associated risks. ${ }^{10,19,20,25,26}$

In symptomatic patients, the presence of symptoms is a primary indication for surgery, especially in case of cardiac tamponade or after blunt trauma. ${ }^{10,23}$ The most common symptoms are fever, pericarditis and pericardial effusion, arrhythmia, thrombi, and neurotic manifestations, mainly anxiety. Among symptoms, fever may result from infection of pericardium or endocardium or sepsis, particularly from contaminated fragments. ${ }^{25-27}$ Pericarditis and recurrent pericardial effusion result from missile penetration into the pericardium and are common if the patient was conservatively treated at the time of trauma. ${ }^{28}$ Recurrent pericarditis may result from inflammation of the epicardium due to the movements of the heart against the foreign body, causing intrapericardial bleeding and inflammation. ${ }^{10,28}$ Arrhythmia or cerebrovascular accident due to embolization of the foreign body and thrombus formation are indications for surgical removal irrespective of the nature of the foreign body. ${ }^{10,18,29,30}$ The presence of neurotic manifestations is of particular interest: comprehensibly, some patients become anxious about the presence of a cardiac foreign body, as 
observed in one case in our experience. This, in our opinion, may be an indication for surgical removal. ${ }^{10,27,31}$

In asymptomatic patients, indication for surgery depends on the nature and location of the foreign body. Patients with the foreign bodies completely embedded in the myocardium or in the pericardial space usually remained symptom-free for a time. ${ }^{10}$ Symbas and colleagues ${ }^{10}$ in their review suggest that these foreign bodies could left in place. Our experience with 4 patients confirms this. Differently, intracavitary missiles or missiles partially embedded in the myocardium, particularly in the left side of the heart, should be removed because of the risk of infection or embolization. ${ }^{10}$ A possible exception may be missiles incidentally diagnosed years after the trauma.

Finally, the iatrogenic nature of some foreign bodies is associated with medicolegal implications that sometimes can influence the choice between surgical or conservative treatment.

Surgical options depend on the localization of the foreign body and the need for cardiopulmonary bypass. ${ }^{20}$ Some authors suggest a median sternotomy approach in particular if pericardiectomy is needed. ${ }^{31,32}$ Culliford and colleagues ${ }^{32}$ found that in these cases median sternotomy results in decreased morbidity and reduced hospitalization compared with thoracotomy. ${ }^{32}$ The same results were obtained by LeMarie and colleagues. ${ }^{28}$

In the present series, the surgical approach was thoracotomy in 7 cases ( 2 with cardiopulmonary bypass), median sternotomy in 2 cases ( 1 with cardiopulmonary bypass), and percutaneous access in 1 patient. In our opinion, cardiopulmonary bypass should be instituted only if strictly necessary. Criteria for the need of cardiopulmonary bypass include the time interval between diagnosis or treatment and the injury and the precise location of the missile within the heart, along with its relationship with the cardiac cavities. In our experience, all missiles that have been lodged for many years in the heart, those that presented with a partially exposed portion outside the cardiac cavities, or those that could be easily located by finger palpation could be approached without cardiopulmonary bypass. Percutaneous removal is indicated in the presence of catheter fragments and should be done as initial treatment, not precluding subsequent surgery. $3,16,17,33,34$ Conservative management requires follow-up, anticoagulation, and antibiotic prophylaxis. $^{23}$

To conclude, the management of foreign bodies in the heart should be discussed on an individual basis:

1. Symptomatic foreign bodies manifesting with infection, arrhythmia, or neurotic manifestations should be removed irrespective of their location.

2. Asymptomatic foreign bodies diagnosed immediately after the injury with an associated risk of infection, embolization, or erosion should be removed.
3. Asymptomatic foreign bodies without associated risks or diagnosed late after the injury may be treated conservatively, particularly if they are completely embedded in the myocardium or in the pericardium and pericardial space.

\section{References}

1. Simbas PN, Vlasis-Hale SE, Picone AL, Hatcher CR Jr. Missiles in the heart. Ann Thorac Surg. 1989;48:192-4.

2. Michelassi F, Pietrabissa A, Ferrari M, Mosca F, Vargish T, Moosa HH. Bullet emboli to the systemic and venous circulation. Surgery. 1990;107:239-45.

3. Singer J, Joyce P, Brems J. Basket removal of intraatrial catheter after liver transplantation: technical note. Cardiovasc Intervent Radiol. 1989;12:230-1.

4. Crie JS, Hajar R, Folger G. Umbilical catheter masquerading at echocardiography as a left atrial mass. Clin Cardiol. 1989;12:728-30.

5. Di Carlo I, Fisichella P, Russello D, Puleo S, Latteri F. Catheter fracture and cardiac migration: a rare complication of totally implantable venous devices. J Surg Oncol. 2000;73:172-3.

6. Kelly IM, Boyd CS. Buckling of tethering catheter causes migration of a temporary caval filter to the right atrium. Clin Radiol. 1999;54:398401.

7. Mathey J, Binet JP. Sept cas des corps etrangers intracardiaques, intramyocardiques ou intrapericardiques operées. Presse Med. 1962; 70:57-9.

8. Tubbax H, Hendzel P, Sergeant P. Cardiac perforation after Kirschner wire migration. Acta Chir Belg. 1989;89:309-11.

9. Korompai FL, Hayward RH, Knight WL. Migration of temporary epicardial pacer wire fragment retained after a cardiac operation. J Thorac Cardiovasc Surg. 1987;94:446-7.

10. Symbas PN, Picone AL, Hatcher CR, Vlasis-Hale SE. Cardiac missiles: a review of the literature and personal experience. Ann Surg. 1990;211:639-8.

11. Wainsztein N, Mautner B. A bullet in the heart. Circulation. 1999; 100:1361.

12. Hasset A, Moran J, Sabiston DC, Kisslo J. Utility of echocardiography in the management of patients with penetrating missile wounds of the heart. J Am Coll Cardiol. 1986;7:1151-6.

13. Amsell BJ, Van Der Mast M, De Bock L, van Haasen R, Beeckman C. The importance of two dimensional echocardiography in the location of a bullet embolus to the right ventricle. Ann Thorac Surg. 1988;46: 102-3.

14. Fyfe DA, Edgerton JR, Chaikhowi A, Kline CH. Preoperative localization of an intracardiac foreign body by two-dimensional echocardiography. Am Heart J. 1987;113:210-2.

15. Reeves WC, Movahed A, Chitwood R, Williams M, Jolly SR. Utility of precordial, epicardial and transesophageal two-dimensional echocardiography in the detection of intracardiac foreign bodies. Am J Cardiol. 1989;64:406-9.

16. Best IM. Transfemoral extraction of an intracardiac bullet embolus. Am Surg. 2001;67:361-3.

17. Kaushik VS, Mandal AK. Non-surgical retrieval of a bullet embolus from the right heart. Catheter Cardiovasc Interv. 1999;47:55-7.

18. Harken DE, Williams AC. Foreign bodies in relation to thoracic blood vessels and heart: migratory foreign bodies within blood vascular system. Am J Surg. 1946;72:80-90.

19. Shirani J, Zafari AM, Hill VE, Roberts WC. Long asymptomatic survival with a bullet adjacent to the left main coronary artery, the only site of atherosclerotic plaque in the coronary tree. Am Heart J. 1994; 128:1043-4.

20. Actis Dato GM, Aidala E, Zattera GF. Foreign bodies in the heart: surgical or medical therapy? Ann Thorac Surg. 1999;68:291-2.

21. Mattox KL, Beall AC, Ennix CL, DeBakey ME. Intravascular migratory bullets. Am J Surg. 1979;137:192-5.

22. Ledgerwood AM. The wandering bullet. Surg Clin North Am. 1977; 57:97-108.

23. Gandhi SK, Marts BC, Mistry BM, Brown JW, Durham RM, Mazuski 
JE. Selective management of embolized intracardiac missiles. Ann Thorac Surg. 1996;62:290-2.

24. Shannon JJ, Vo NM, Stanton PE Jr, et al. Peripheral arterial missile embolization: a case report and 22-year literature review. J Vasc Surg. 1987;5:773-8.

25. Balbi M, Bertero G, Bellotti S, Rolandelli ML, Caponetto S. Rightsided valvular endocarditis supported by an unexpected intracardiac foreign body. Chest. 1990;97:1486-8.

26. Hong-Barco P, O’Toole J, Gerber ML, Domat I, Moquin M, Jackson SC. Endocarditis due to six entrapped pacemaker leads and concomitant recurrent coronary arteriosclerosis. Ann Thorac Surg. 1988;46:97-9.

27. Mourton JR, Reul GJ, Arbegast NR, Okies JE, Beall AC. Bullet embolus to the right ventricle. Report of three cases. Am J Surg. 1971;122:584-90.

28. LeMarie SA, Wall MJ, Mattox KL. Needle embolus causing cardiac puncture and chronic constrictive pericarditis. Ann Thorac Surg. 1998; 65:1786-7.
29. Rossi P, Arata FM, Bonaiuti P, Pedicini V. Fatal outcome in atrial migration of the Tempofilter. Cardiovasc Intervent Radiol. 1999;22: 227-31.

30. Willemsen P, Kuo J, Azzu A. Dysrhythmia from an intrapericardial air gun pellet: a case report. Eur J Cardiothorac Surg. 1996;10: 461-2.

31. Van Way CW. Intrathoracic and intravascular migratory foreign bodies. Surg Clin North Am. 1989;69:125-33.

32. Culliford AT. Surgery for chronic constrictive pericarditis. In: Roberts AJ, editor. Difficult problems in adult cardiac surgery. Chicago: Year Book Medical Publishers; 1985. p. 317-24.

33. Dakshinamurti S, Ducas J, Odim JN. Retrieval of Silastic catheter fragment from heart in septic thromboembolic complicating aplastic anemia. Can J Cardiol. 1996;12:794-6.

34. Pecirep DP, Hopkins HR. Removal of a bullet from the right heart using controlled embolization to a peripheral vein. Ann Thorac Surg. 1994;58:1748-50.

\section{Bound volumes available to subscribers}

Bound volumes of The Journal of Thoracic and Cardiovascular Surgery are available to subscribers (only) for the 2003 issues from the Publisher, at a cost of $\$ 134.00$ for domestic, $\$ 165.85$ for Canadian, and $\$ 155.00$ for international subscribers for Vol 125 (January-June) and Vol 126 (July-December). Shipping charges are included. Each bound volume contains a subject and author index and all advertising is removed. The binding is durable buckram with the Journal name, volume number, and year stamped in gold on the spine. Payment must accompany all orders. Contact Mosby, Subscription Customer Service, 6277 Sea Harbor Dr, Orlando, FL 32887, USA; phone 800-654-2452 or 407-345-4000.

Subscriptions must be in force to qualify. Bound volumes are not available in place of a regular Journal subscription. 